\title{
The delivery of nitric oxide in the cardiovascular system: impli- cation for clinical diagnosis and therapy
}

\author{
Tianxiang Ma 1,II, Zhexi Zhang 1,II, Yu Chen ${ }^{1}$, Haoran Su ${ }^{1}$, Xiaoyan Deng ${ }^{1}$, Xiao Liu 1,", Yubo Fan ${ }^{1, *}$ \\ 1 Key Laboratory of Biomechanics and Mechanobiology (Beihang University), Ministry of Education, Beijing \\ Advanced Innovation Center for Biomedical Engineering, School of Biological Science and Medical Engi- \\ neering, Beihang University, Beijing, 100083, China. \\ II These authors contributed equally to this work. \\ * Correspondence: liuxiao@buaa.edu.cn (Dr. Liu); yubofan@buaa.edu.cn (Dr. Fan)
}

\begin{abstract}
Nitric oxide (NO) is a key molecule in cardiovascular homeostasis and its abnormal delivery is highly associated with the occurrence and development of cardiovascular disease (CVD). The assessment and manipulation of NO delivery is crucial to the diagnosis and therapy of CVD, such as endothelial dysfunction, atherosclerotic progression, pulmonary hypertension, and cardiovascular manifestations of Coronavirus (COVID-19). However, due to the low concentration and fast reaction characteristics of $\mathrm{NO}$ in cardiovascular system, the clinical applications centered on the NO delivery are challenging. In this tutorial review, we first summarized the methods to estimate the in vivo NO delivery process based on the clinical images and mathematical modeling to assess the endothelial function and vulnerability of atherosclerotic plaque. Then, the emerging bioimaging technologies that have the potential to directly measure the arterial NO concentration were discussed, including the Raman spectroscopy and electrochemical sensor. Aside from the diagnostic methods, therapies aimed at controlling NO delivery to regulate CVD were reviewed, including the inhaled NO therapy to treat the pulmonary hypertension and COVID-19, stem cell therapy and NOreleasing platform to treat endothelial dysfunction and atherosclerosis.
\end{abstract}

Keywords: Nitric oxide delivery; mathematical modeling; Flow-mediated dilation; Inhaled NO therapy; Stem cell therapy; NO-releasing platform

\section{Introduction}

Cardiovascular disease (CVD) is a major cause of human morbidity and death[1,2]. Nitric oxide (NO) has crucial roles in cardiovascular homeostasis, which is practiced in a dose-dependent manner. Both high and low local concentrations of NO may induce the development of CVD[3,4]. The main sources of cardiovascular nitric oxide (NO) are the endothelial nitric oxide synthase (eNOS) and inducible nitric oxide synthase (iNOS) from L-arginine and oxygen[5,6]. The eNOS expressed in endothelial cells is the main source of NO in physiological arteries, depending on the mechanotransduction of wall shear stress (WSS)[7], and the dysfunction of endothelium, the single layer of cells that forms the lining of blood vessels, is thought to underpin most types of CVD[8-10]. In physiological condition, the generated NO would fast diffuse into the adjacent arterial wall, and lead to the vasodilation by relaxing vascular smooth muscle[11] (figure 1a). However, the impaired endothelial function would insufficiently release $\mathrm{NO}$ and increase the atherogenic biochemical localization[12-14]. In the pathological arteries, such as the atherosclerosis, the anti-inflammatory M2-polarized macrophages in the lipid pool would be activated to the pro-inflammatory M1-polarized macrophages and express iNOS[15,16] (figure 1b). Excessive NO produced by iNOS would rapidly form reactive nitrogen species (RNS) with the combination of reactive oxygen species (ROS), increasing the risk of plaque rupture[17]. Therefore, the diagnostic indexes derived from NO delivery process can potentially assess the endothelial function and the development the atherosclerosis and other types of CVD. 
Aside from the endogenous delivery, recent advances in exogenous NO releasing and scavenging technologies have initially realized the modulation of NO delivery process[18-24]. For example, the inhaled NO therapy can induce the vasodilation of pulmonary vessels, aimed to improve the oxygenation. Besides, drugs as organic nitrates, inorganic nitrates/nitrites and other donors can release NO[25], L-NIL, L-NNA and other scavengers can deplete NO[26]. In addition, a few types of stem cells such as the mesenchymal stem cells (MSCs), are also capable of modulating the local NO delivery process via paracrine mechanisms[27]. However, due to the difficulties in the accurate measurement and regulation of arterial NO delivery process, few US Food and Drug Administration (FDA)approved diagnostic and therapeutic methods have been proposed for CVD up to now[28]. In this tutorial review, we summarized the combination of flow-mediated dilation (FMD)[29,30], mathematical simulations[31-34], and novel NO bioimaging techniques that can assess the NO delivery, thereby evaluating the endothelial dysfunction and its derived CVD[35]. The NO-related therapeutic methods, including the inhaled therapy, stem cell therapy and NO-releasing platform were also reviewed. We particularly focused on the recent progresses and implications of assessing and modulating the $\mathrm{NO}$ delivery in the above clinical diagnostic and therapeutic methods.

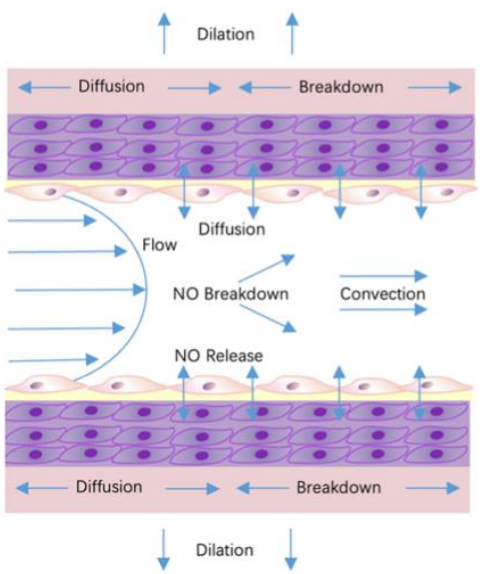

(a)

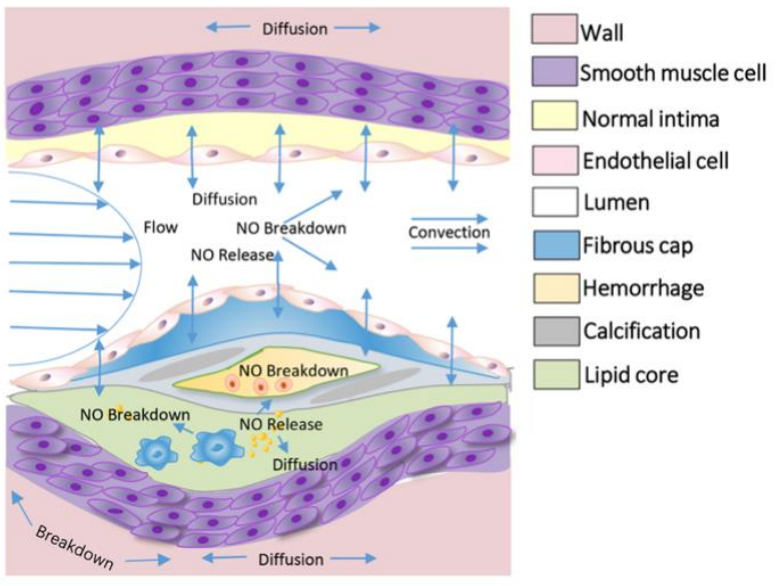

(b)

Figure 1. The delivery process of nitric oxide (NO) in physiological and atherosclerotic arteries. (a) In physiological site, $\mathrm{NO}$ is mainly released by the endothelial cells modulated by the shear flow. The released NO would be fast delivered to the neighboring arterial wall, leading to the vasodilation. The diffusion, convection, reaction processes of NO are shown in the schematic diagram; (b) In atherosclerotic arteries, besides the delivery process in physiological arteries, massive NO would release from the activated macrophages in the lipid core and the released NO would be synchronously consumed by the hemoglobin in the intraplaque hemorrhage.

\section{The assessment of nitric oxide delivery as therapeutic tool}

2.1. The implication of nitric oxide delivery analysis in diagnosing the endothelial function and atherosclerosis development

The complex arterial mass delivery process is hard to experimentally investigate in vivo, and mathematical analysis of the process has been widely accepted as a powerful tool for studying the delivery of low-density lipoprotein[36-38] and thrombus[39-41]. However, due to the low concentration $(n M-\mu M)$ and high chemical activity natures, the process of NO delivery is quite different from the above substances: the production, transmission and reaction processes are all nonnegligible and should be simultaneously simulated.

Based on the pioneer works of NO delivery simulation[42-44], Fadel et al.[45] and Plata et al.[46] further considered the endothelial NO releasement and convective processes. Then, our group analyzed the NO delivery in a two-dimensional idealized stenosed artery, which considered the effect of blood flow, the transmission and reaction of $\mathrm{NO}$ in lumen and arterial wall. This study found that NO concentration is significantly 
hindered distal to the stenosis, which corresponds to the endothelial dysfunction [33]. The model was then extended to the three-dimensional physiological aorta, based on the imaging data of magnetic resonance imaging (MRI). The results showed that low NO concentration is related to the occurrence of endothelial dysfunction and the high-risk location of atherosclerosis, which is shown in figure 2a[32]. This NO delivery model has been initially verified by the in vitro animal experiment[47]. Besides, the NO distribution in the idealized arterioles was evaluated with the further consideration of flowing red blood cells. The study illustrated that the permeability of red blood cells would largely determine the NO delivery process in microvessel[48,49]. However, none of the above studies have assessed the NO delivery process in the pathological artery. We recently considered the effect of atherosclerotic components on NO delivery, including the NO production by the activated macrophages in lipid pool, the inorganic calcification, and the breakdown of $\mathrm{NO}$ due to the hemoglobin in the intraplaque hemorrhage. We found that NO is unevenly distributed with high level around the atherosclerotic plaque (figure $2 b$ ), which potentially indicates the vulnerability of plaques[31].
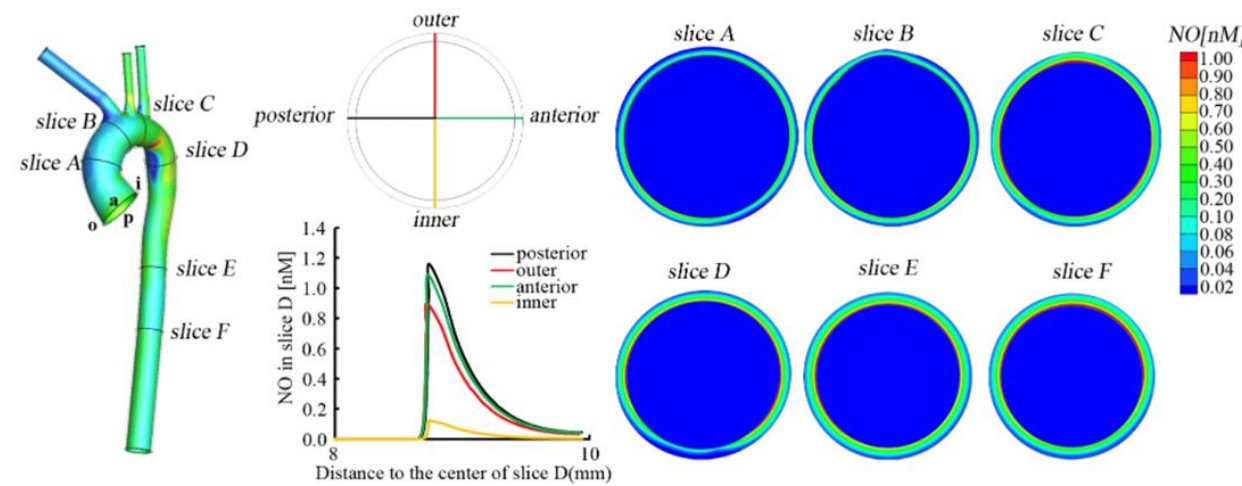

(a)

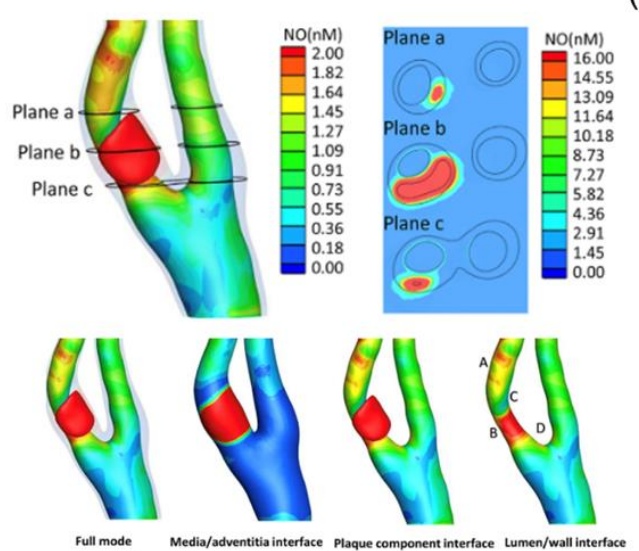

(b)

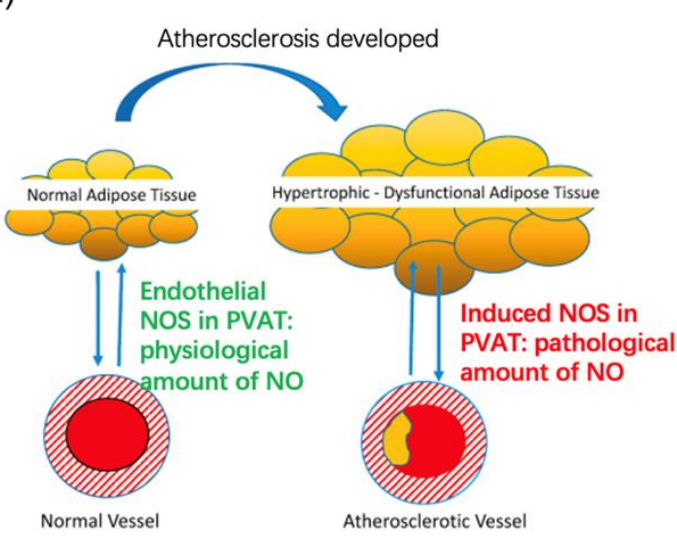

(c)

Figure 2. The nitric oxide (NO) delivery analysis to assess the atherosclerotic development. (a) NO distributions of six representative slices in the physiological aorta. The NO distribution at slice $\mathrm{D}$ is the most uneven, corresponding to the atherosclerosis prone site[32]; (b) The high NO concentration in lipid pool is illustrated. The NO distribution around the atherosclerotic plaque is quite uneven, with the high level at point $\mathrm{A}$ and point $\mathrm{B}$ and the low level at point $\mathrm{C}$ and point $\mathrm{D}$; (c) The effects of NO delivery by the physiological and atherosclerotic perivascular adipose tissue (PVAT). Panel b is reproduced with permission from ref[31], Elsevier. Panel $\mathrm{c}$ is adapted with permission from ref[50], Elsevier.

In conclusion, based on the clinical images and the mathematical modeling of NO delivery, the in vivo distribution of NO can be calculated to diagnostically predict the endothelial dysfunction and atherosclerotic progression. However, aside from the lumen, 
arterial wall and atherosclerotic plaque, more and more studies have shown that the perivascular adipose tissue (PVAT) could also affect the NO delivery[51]. For the physiological arteries, the eNOS expressed in PVAT would release moderate amount of NO to stabilize the endothelial function[52]. Besides, the activated macrophages in the inflamed PVAT would express iNOS and release massive NO, which may further increase the vulnerability of plaque by synergizing with the effect of lipid core[50]. As far as we are concerned, investigating the exact role of PVAT in atherosclerosis with numerical modeling may be a promising topic. The schematic diagram illustrating the role of PVAT in regulating the endothelial function and atherosclerotic progression has been shown in figure 2c.

\subsection{The implication of nitric oxide delivery assessment in flow-mediated dilation}

\subsubsection{The overview of flow-mediated dilation and its limitation}

Flow-mediated dilation (FMD), the measurement of flow and shear stimulated vasodilation, has gradually become an accepted non-invasive approach to assess the endothelial function since it was originally introduced by Celermajer, Deanfield, and colleagues[53-55]. Unlike the direct calculation of NO delivery in modelling as reviewed in section 2.1, the conventional FMD aimed to clinically measure the vasodilation and reflect the overall NO delivery process. Technologically, the conduit artery, usually the brachial artery, is occluded by a sphygmomanometer cuff to supra-systolic pressures (typically between 200 and 300 $\mathrm{mmHg}$ ), 5 minutes distal to the ultrasound probe[30]. After the temporary ischaemia ends as the cuff releases, the peripheral resistance would intensively reduce and lead to the increasement of blood flow and shear stress. The shear-induced $\mathrm{NO}$ released by endothelium would dilate the conduit artery, reflecting the endothelial function.

The magnitude of FMD is conventionally described by the percentage flow-mediated dilation index (FMD\%), calculated by the relative increasement of examined artery between the basal and maximal dilated moment. However, FMD\% is not only determined by the endothelial function, but also affected by the large individual differences in measuring process, blood flow, blood pressure, and arterial diameter, limiting its diagnostic significance[29,30]. Two optimization strategies have been widely proposed to decrease this problem. The first is to standardize the test procedure, which has been recently proposed by Thijssen and colleagues[30]. The second is to normalize the measured FMD\% to preclude the interference factors other than endothelial function through clinical experiences and statistical methods, such as calculating the area under the curve of shear[56,57], analysis of covariance[58,59] and others[60,61].

2.1.2. Mathematical modeling of NO delivery in flow-mediated dilation to enhance the specificity of endothelial function

Recent studies have drawn increasing attention to exclude the confounding factors other than endothelial function by mathematical modeling the NO delivery process. It should be mentioned that the vasodilation must be considered in addition to the above models reviewed in section 2.1 when analyzing the FMD process.

Kamiyama and colleagues pioneered the NO delivery model of FMD[62]. The model has the ability to exclude the effect of individual differences in arterial stiffness from FMD \% to enhance the specificity of endothelial function. The model considered the molecular dynamics during NO delivery including the shear-induced NO releasement, the changes of cyclic guanosine monophosphate (cGMP), $\mathrm{Ca}^{2+}$, and mechanosensitive channel activity[63]. Aside from modeling the NO delivery from the small-scale mechanism, other studies modeled this process in large scale. For example, the exposure-response model was established based on the simplified physical formula to describe the NO delivery and vasodilation, which uniquely considers the FMD time course and excludes the interference of shear-exposure from the endothelial function[64]. This model was recently extended to quantitatively reveal the interfaces of blood pressure and arterial stiffness on assessing the endothelial function from FMD\%[65,66]. 
Aside from the exposure-response model, Sidnawi et al. further considered the vasodilating effect of NO by describing the arterial stiffness as a function of WSS, and derived the new parameters other than FMD\% to represent the time response of arterial diameter and the arterial resistance to a changing wall shear stress $[67,68]$. Besides, our group modeled the NO delivery process based on the advection-diffusion-reaction equation of NO transport, and considered the deformation of arterial wall whose stiffness is determined by NO concentration. The model has the ability to calculate the personalized expected FMD \% when the endothelium is totally healthy with the consideration of individual differences in blood flow, blood pressure and arterial diameter. With the normalization of the measured FMD\% by the expected FMD\%, the difference between the real and healthy endothelial function can be revealed, and the individual differences in the personalized data can be simultaneously excluded[69].

The above researches mainly focused on simulating the NO delivery process from a mathematical point of view, and initially show the potential to enhance the specificity of endothelial function in the FMD test. However, due to the bottleneck of NO measurement technology, current models inevitably rely on assumptions and lack direct verification, which limit the clinical translation. For instance, the endothelial NO releasement is assumed to be same for each individual. Therefore, in Section 2.3, we focused on emerging bioimaging techniques that have the potential to directly measure NO concentration in arteries.

\subsection{Direct cardiovascular bioimaging of nitric oxide}

In section 2.1 and 2.2, we review the methods to estimate the NO delivery process based on the numerical modeling and flow-mediated dilation. However, it is still challenging to directly measure the NO concentration in arteries due to its low concentration and fast reaction characteristics.

The Raman spectroscopy is a potential choice for measuring the NO delivery process by detecting the molecular structure without labeling. The surface-enhanced Raman spectroscopy (SERS)is a great choice to analyze the molecule with low concentration, which is shown in Fig.3(a). Cui et al. designed a kind of reaction-based SERS nanoprobes for the detection of intracellular NO with $o$-phenylenediamine-modified gold nanoparticles. They utilized this technology to measure the NO releasement by macrophages (iNOS) with the temporal resolution of 30s and sensitivity of 100nM[70]. Following this work, Xu et al. designed a ratiometric SERS probe with the synthesis of compound 3,4-diaminobenzene-thiol, and achieved the NO sensitivity of 54nM[71]. Recently, Chen et al. modified the SERS sensor with gold nanoparticles and synthesized 3,4-diaminophenylboronic acid pinacol ester to further enhance the NO detection range to the level of $0-105 \mathrm{nM}$. One of the features of their work is that peroxynitrite (ONOO-) synthesized by the overproduced $\mathrm{NO}$ and reactive oxygen species (ROS) can be synchronously measured, which is the critical component increasing the rupture risk of plaque[72]. Since SERS is limited to the in vitro measurement, a few studies have tried to use the fiber-optic Raman spectroscopy to collect the in vivo chemical signals (Fig.3(b))[73,74]. However, due to the low level of concentration, the NO measurement with the fiber-optic Raman spectroscopy has not been realized yet.

Electrochemical methods are more mature compared with the Raman spectroscopy for the NO delivery detection. Researchers are constantly working on modifying the electrodes to better measure NO in various settings[75], of which the mechanism is transferring the NO oxidation on electrode surface to the signal of measurable current. The pioneered work monitored the NO delivery process under the circumstances of different vasodilator drugs in the guinea pig isolated hearts by Fujita et al. [76]. The first achievement of in vivo measurement was the catheter NO sensor, which was used to measure the NO concentration in human coronary circulation in real time to evaluate endothelial function[77]. They claimed that this sensor can be further utilized to achieve the diagnosis of atherosclerosis. Besides, an acupuncture microsensor needle made of gold film and com- 
bined with iron porphyrin-functionalized graphene complex was then proposed to monitor the NO signal in rat through puncture[78]. The aforementioned electrochemical NO sensors are non-deformable and non-biodegradable, which may cause severe irritation and infection complications. Recently, Li et al. designed a flexible and degradable sensor to achieve real time measuring of NO delivery, with a wide detection range, high temporal resolution, and high biocompatibility as shown in Fig.3(c). They claimed that the NO sensors could be further combined with the electrical stimulators to realize multifunctional physiological assessment[79].

One of the main drawbacks of the electrochemical method is that it is limited to the invasive assessment of NO delivery on the endothelium, and cannot measure the NO concentration in arteries and atherosclerotic plaques. To fix this problem, the numerical modeling of NO delivery may be combined with the electrochemical measurement, which is capable of predicting the inside $\mathrm{NO}$ concentration distribution based on the measured value.

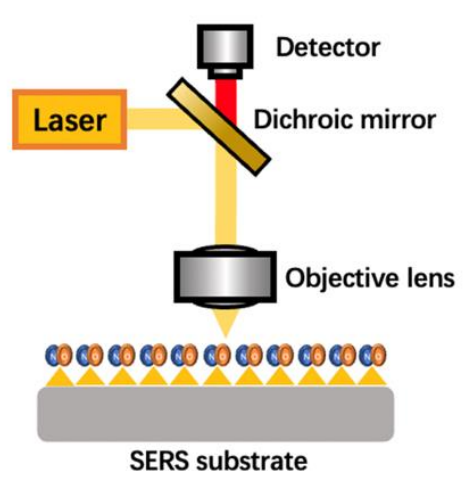

(a)

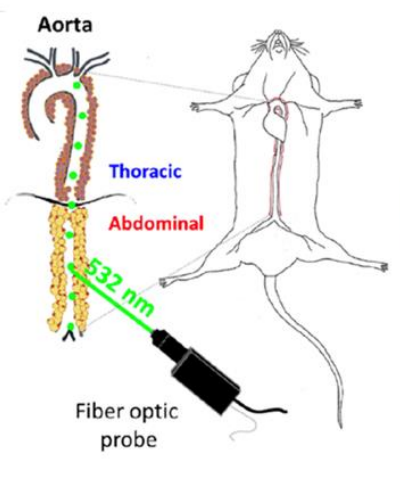

(b)
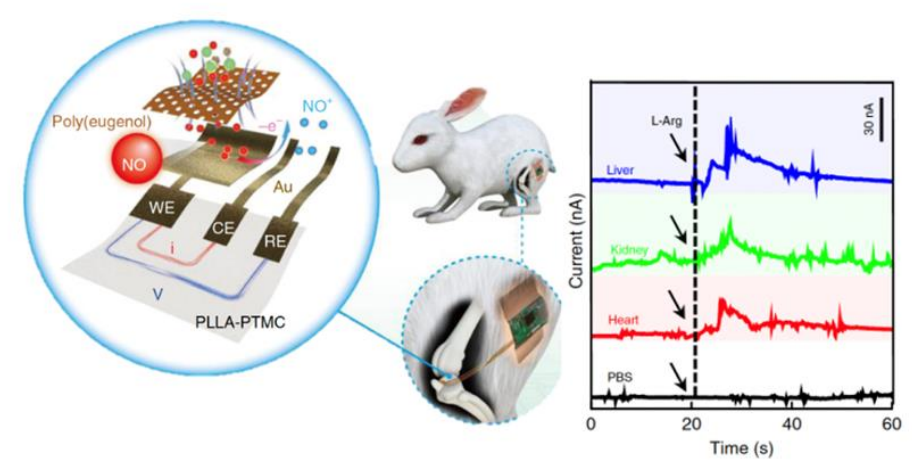

(c)

Figure 3. The emerging technologies to directly measure the cardiovascular nitric oxide. (a) The schematic diagram of surface-enhanced Raman spectroscopy (SERS). The large enhancement in the Raman signal can be observed when nitric oxide (NO) is absorbed or lies close to the enhanced field at the surface; (b) The cardiovascular application of fiber-optic Raman spectroscopy[74]; (c) The flexible and degradable electrochemical sensor to achieve real time measuring of NO delivery in rabbit, and the signal of NO concentration in various tissues[80].

\section{Nitric oxide delivery related therapeutic approaches}

Aside from assessing nitric oxide (NO) delivery to diagnose CVD, the multiple function of NO has also initiated large interests in the exploration of solutions to therapeutically modulate the NO releasement.

3.1 The inhaled nitric oxide therapy to treat the pulmonary hypertension and Coronavirus (COVID-19)

The inhaled NO has the effects of relaxing pulmonary vessels, and increasing the pulmonary blood oxygenation. It is the only NO-related method that has been formally approved by the US Food and Drug Administration (FDA), European Medicine Evaluation Agency, and Japanese Ministry of Health, Labour and Welfare (MHLW) for the clinical treatment of severe persistent pulmonary hypertension of the newborn[81,82], The potential outcomes of inhaled NO therapy for adults have also been continuously investigated[83].

The main limitation of inhaled NO therapy is that the optimal dosed threshold remains unclear, which would lead to the long-term impairments, such as the neurodevelopmental disability [84]. It is with this backdrop that, Carter et al. designed a MRI-compatible NO delivery device, which realized the simultaneous nitric oxide inhalation and measurement of vasodilation[85]. Schafer et al. further quantitatively investigated the correlation between the inhaled NO and hemodynamic changes in the intracardiac flow with four-dimensional-flow MRI[86]. They claimed that this method can link the quantity of delivered NO to the corresponding therapeutic effects, which may help the choice of dose 
in clinical decision-making. The quantitative process of NO delivery and exchange in lung based on the numerical modeling has also been explored[87]. However, the systematic modeling of the inhaled NO, the NO delivery in trachea and arteries, and the vasodilating effects of NO has not yet been achieved.

Recently, the possible role of inhaled NO in the therapy of Coronavirus (COVID-19) has received high attention. Experimental and clinical evidences suggest that NO is beneficial to the treatment of the coronavirus-mediated acute respiratory syndrome due to its vasodilating effect $[88,89]$. Besides, the inhaled NO therapy may also prevent the pulmonary vascular dysfunction, which is one of the major cardiovascular manifestations of COVID-19[90]. Unlike the inhaled NO therapy of pulmonary hypertension, the inhalation of $\mathrm{NO}$ in short bursts at high concentrations is recommended to effectively prevent the progression of COVID-19[91].

3.2 The implication of nitric oxide delivery manipulating with stem cell related treatment

Stem cell refers to the undifferentiated cell with indefinite division potential to differentiate into different types of cells and tissues[92], which are widely studied in regenerative medicine, including restoring endothelial function and treating the atherosclerosis.

Mesenchymal stem cell (MSC) is one of the most attractive therapeutic agents in various diseases[27,93,94]. Massive studies have illustrated that MSCs practice in a positive role in the treatment of CVD by improving the local nitric oxide (NO) level, thereby restoring endothelial function[27] (figure 4a). Firstly, the skin-derived MSCs can promote NO production by releasing vascular endothelial growth factor, thus enhancing the vasodilation[95,96]. Besides, MSCs can enhance the eNOS level in the oxidized low-density lipoprotein-exposed endothelial cells by secreting IL8/MIP-2[97]. Secondly, for the developed atherosclerotic plaque with lipid core, MSCs can not only improve the eNOS expression of the endothelium, but also significantly decrease the iNOS immunoreactivity by regulating the macrophage polarization in lipid core, thereby reducing the risk of plaque rupture via paracrine mechanisms[98-100]. Besides, MSCs can differentiate into cardiovascular cells and promote angiogenesis [101]. Aside from MSCs, the induced pluripotent stem cell[102,103] and vascular wall progenitor cell[104] can also be promising in the therapy of CVD. Moreover, the stem cell-derived exosomes (figure 4a) also have the potential of protecting endothelial cells by promoting NO production, which can be regarded as an effective and powerful alternative to stem cell in CVD therapy[105-111].

The stem cell therapy and the related NO delivery process is hard to control, e.g. the unknown dose range for the treatment of atherosclerosis[97]. Furthermore, there is no consensus on the optimal selection of stem cells delivery methods[112]. Local delivery, a method of injecting cells into target tissues, is conducive to precise delivery. But it still has some limitations such as the clinical risk of delivering massive cells to target tissue[113].Combining stem cells with NO release platform provides a novel regenerative medicine approach to improve the local NO delivery environment (figure 4b)[28]. The NO released from the platform can interact with the stem cells and then improve the outcomes of the stem cell therapy (figure 4c)[114-116]. Through choosing the proper NO-releasing platform, the modulation of $\mathrm{NO}$ delivery by stem cells may be more effective. 


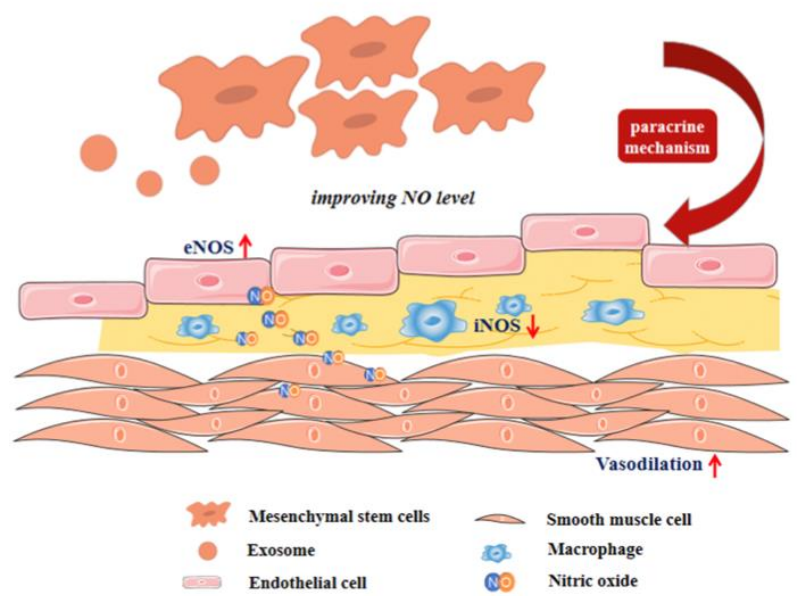

(a)

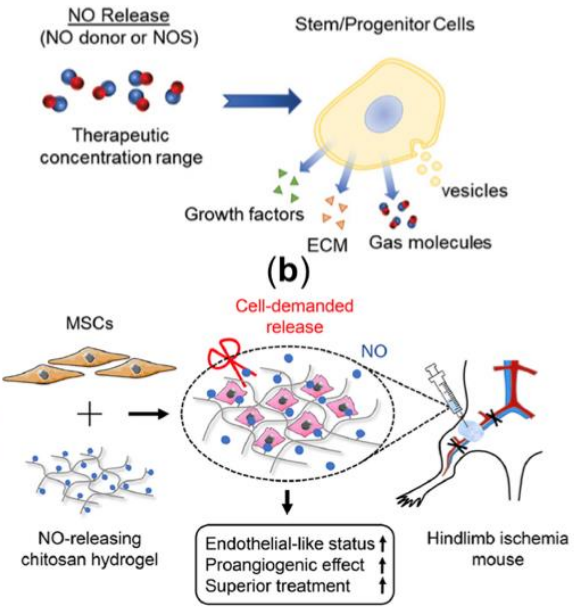

(c)

Figure 4. The nitric oxide (NO) delivery related stem cell therapy. (a) The protective role of mesenchymal stem cells and exosomes in CVD by improving the eNOS expression of the endothelium and decreasing the iNOS expression of the macrophages; (b) The effect of NO release on stem cell; (c) The combination of mesenchymal stem cells with NO-releasing chitosan hydrogel enhanced the therapeutic function in hindlimb ischemia. Panel $b$ is adapted with permission from ref[28], Wiley Online Library. Panel c is adapted with permission from ref[116], Elsevier.

\subsection{The implication of nitric oxide delivery manipulating with releasing platform}

\subsubsection{The overview of nitric oxide releasing platform and its limitations}

The most widely used exogenous NO donors are the organic nitrates (e.g. nitroglycerin[117]). However, the features of unfavorable pharmacokinetics and development of tolerance during chronic administration of organic nitrates might lead to the increased synthesis of reactive oxygen species (ROS) and the endothelial dysfunction[118-120]. To avoid the side effect of organic nitrates, inorganic nitrates/nitrites[121,122], nicorandil[123,124] and molsidomine[125] were gradually developed, showing promising effects to improve the NO-mediated vasodilation and atherosclerotic plaque stability. Besides, N-diazeniumdiolate (NONOate) has the unique advantages of high efficiency, which is capable of spontaneously releasing twice the amount of $\mathrm{NO}$ as the donor, and the broad choices of half-life (2s to 20h)[126,127]. Incorporating polymers into NO releasing platform allows transporting $\mathrm{NO}$ in a more continuous manner, including micelles, dendrimers, star-shaped polymers, and polymeric nanoparticles [128]. Micelles use amphiphilic polymers to synthesize concentration-dependent structures through hydrophilic or hydrophobic interactions, but have low encapsulation efficiency[128-131]. Dendrimers are three-dimensional hyperbranched globular nanopolymeric architectures with advantages of narrow polydispersity index, controllable structure and availability of multiple functional groups at the periphery[132-134]. Star-shaped polymer shows a more stable manner compared with micelles, which is also easier to synthesize than dendrimers[128,135,136]. Polymer nano-/micro-/milli-particles can encapsulate NO donors instead of covalent attachment, which can improve the stability (figure 5a)[137-139]. Nanoparticles are attempted to be synthesized with NO donors and non-polymeric substances to deliver biomedical cargo, including the metallic and nonmetallic nanoparticles[140-142]. For example, incorporating catalytic copper nanoparticles with S-nitroso-Nacetylpenicillamine can release $\mathrm{NO}$ from the blended donor and utilize the endogenous donors in circulation (figure 5b)[148], the modification of NO-releasing mesoporous silica nanoparticles with aminosilane can achieve appreciable levels of NO with tunable NO release durations[143], etc.

Because NO delivery must be administered in the correct dose, proper location and time[120] to achieve the expected therapeutic effect, the clinical applications and efficacy of the above NO donors have been restricted due to difficulties to control the drug release 
and achieve targeted delivery [127,144]. Firstly, the in vivo release kinetics of NO donors vary greatly with the in vitro experiments[145]. Secondly, the produced NO will diffuse randomly in the body, making it difficult to reach the expected spatial and temporal concentration in the target tissue. Inversely, it may cause adverse effects due to the enrichment of nitric oxide in non-target tissues. For example, high concentration of Fe3O4 nanoparticles surface-coated with aminoguanidine can increase NO level to improve endothelium function while low concentration can induce significant decrease in NO production and promote plaque vulnerability[146], showing potential toxicity on pathological arteries. Hence, the concentration of nanoparticle needs to be controlled within a safe range. Besides, taking into account the individual differences, spatiotemporal distribution of NO in the target tissues (such as atherosclerotic plaques) and in the expected healthy state varies greatly[31].

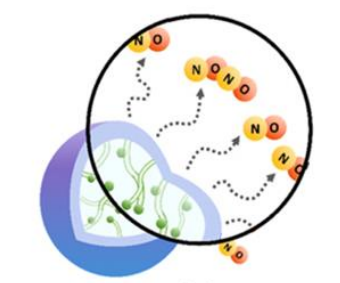

(a)

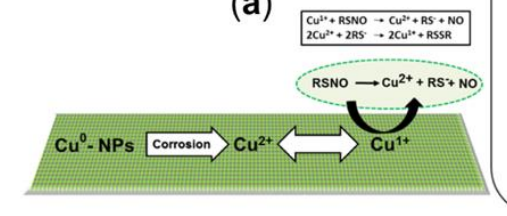

(b)

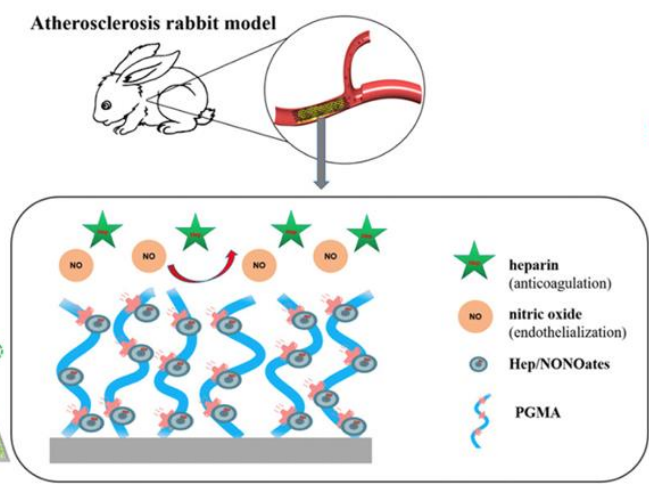

(c)

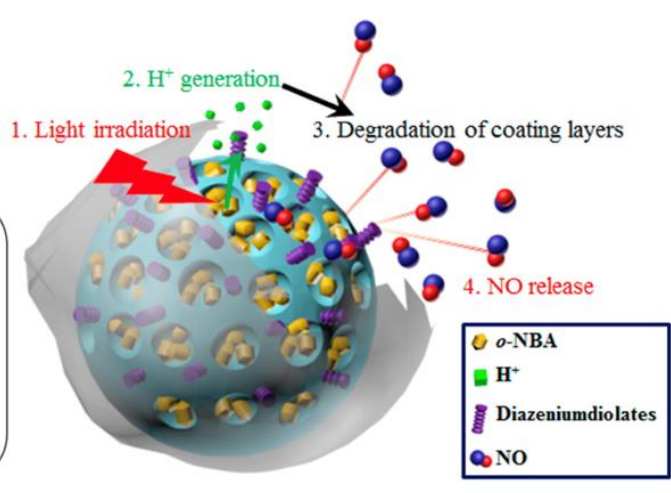

(d)

Figure 5. The NO releasing platforms to manipulate the cardiovascular nitric oxide delivery. (a) Branched polyethylenimine diazeniumdiolate (BPEI/NONOate) was encapsulated into PLGA nanoparticles to release NO in a sustained manner; (b) The mechanism of NO release from the combination of catalytic copper nanoparticles and S-nitroso- $\mathrm{N}$-acetylpenicillamine; (c) The stent coated with heparin/NONOate nanoparticles (Hep/NONOates) contributed to the long-term release of NO; (d) The light-responsive gatekeeper system for spatiotemporal-controlled NO delivery. Panel a is adapted with permission from ref[147]. American Chemical Society. Panel $b$ is adapted with permission from ref[148]. American Chemical Society. Panel c is reproduced with permission from ref[149]. American Chemical Society. Panel d is reproduced with permission from ref[150]. American Chemical Society.

\subsubsection{The manipulation of NO delivery with $\mathrm{NO}$ releasing platform}

In view of the shortcomings and limitations of NO releasing platform mentioned above in section 3.3.1, three pivotal steps are needed to achieve the spatiotemporal delivery process of $\mathrm{NO}$ with the expected dose, location and time in line with the actual situation of the patient's target tissue.

The first step is to analyze the NO delivery characteristics of the patient-specific target tissue, and design the NO distribution expected to be achieved. As mentioned in section 2.1, mathematical modelling can be utilized to assess the spatial distribution of NO in the target pathological region and expected healthy state for each patient individually, so that NO releasing platform can be targeted to regions with lower local NO concentration comparing with the healthy state. What's more, the inhibitors of nitric oxide can act on regions with higher local NO concentration than the healthy state.

The second step is to use the platform to realize the designed NO transmission. Massive efforts have focused on developing controllable NO release platforms. For example, NO-releasing surface coatings can be applied to various supporting structures such as stents (figure 5c)[151,152] and metal-organic frameworks[153,154] to mimic endothelium function, thus promoting NO release and benefitting the treatment of CVD. Such implants can maintain high NO level at a specific site. And extensive attention is being put on the stimuli-responsive systems, which are expected to fulfill on-demand NO delivery in a spatial-/temporal-/dosage- controlled characteristics[155]. Additionally, using a double 
trigger to control the releasement of NO (figure 5d)[150] may be a feasible solution to guarantee the precise of released location and dose. Besides, utilizing the prodrug strategies[156-161] of targeting NO release allows direct localized therapeutic delivery of a controlled dose via enzyme biocatalysis and provides a promising idea for next generation of local targeted CVD therapy.

The third step is to analyze the NO release process to determine whether it is feasible. After the initial selection of the form of the platform, numerical simulation can be used to simulate the kinetics of the NO delivery, so as to get significant guidance for an optimized design of spatiotemporal delivery strategy to the expected target and improve delivery efficiency. Taking nanoparticle as an example, the complex hemodynamic environment around the target tissue affects whether it can reach the target tissue at the expected dose and thus play the expected role[162,163]. By analyzing the blood flow topology, researchers simulated the WSS-sensitive drug delivery system based on the nanoparticle drugs, which may help to improve drug efficacy[164].

\section{Conclusions}

Our knowledge of assessing the NO delivery process to diagnose cardiovascular disease is expanding to a greater extent. Despite recent advances in the mathematical approaches to estimate the NO delivery process based on the clinical images, the methods to directly measure NO concentration in vivo still remain in preclinical stages. In addition, aside from the FDA-approved NO inhaled therapy, the area of future NO-related therapy is receiving more awareness with the arrival of stem cell treatment and NO-releasing platform. The methods to deliver NO at proper location, time, and amount is extremely crucial. Hence, the combination of mathematical modeling to design the NO distribution and NO-releasing platform to achieve the expected results may represent a potential improvement in the personalized therapy of CVD.

Funding: Please add: This work was funded by the National Natural Science Research Foundation of China (grant nos. 11827803, 31971244, 31570947, 32071311and U20A20390) and the 111 Project (B13003).

Acknowledgments: None.

Conflicts of Interest: The authors declare no conflict of interest.

\section{References}

1. Virani, S.S.; Alonso, A.; Benjamin, E.J.; Bittencourt, M.S.; Callaway, C.W.; Carson, A.P.; Chamberlain, A.M.; Chang, A.R.; Cheng, S.; Delling, F.N. Heart disease and stroke statistics - 2020 update: a report from the American Heart Association. Circulation 2020, 141, e139-e596.

2. Timmis, A.; Townsend, N.; Gale, C.P.; Torbica, A.; Lettino, M.; Petersen, S.E.; Mossialos, E.A.; Maggioni, A.P.; Kazakiewicz, D.; May, H.T. European Society of Cardiology: cardiovascular disease statistics 2019. European heart journal 2020, $41,12-85$.

3. Farah, C.; Michel, L.Y.; Balligand, J.-L. Nitric oxide signalling in cardiovascular health and disease. Nature Reviews Cardiology 2018, 15, 292-316.

4. Burke, A.J.; Sullivan, F.J.; Giles, F.J.; Glynn, S.A. The yin and yang of nitric oxide in cancer progression. Carcinogenesis 2013, 34, 503-512.

5. Chen, J.-y.; Ye, Z.-X.; Wang, X.-f.; Chang, J.; Yang, M.-w.; Zhong, H.-h.; Hong, F.-f.; Yang, S.-1. Nitric oxide bioavailability dysfunction involves in atherosclerosis. Biomedicine \& Pharmacotherapy 2018, 97, 423-428.

6. Xia, Y.; Zweier, J.L. Superoxide and peroxynitrite generation from inducible nitric oxide synthase in macrophages. Proc Natl Acad Sci U S A 1997, 94, 6954-6958, doi:10.1073/pnas.94.13.6954.

7. Su, H.; Liu, X.; Du, J.; Deng, X.; Fan, Y. The role of hemoglobin in nitric oxide transport in vascular system. Medicine in Novel Technology and Devices 2020, 5, 100034, doi:https://doi.org/10.1016/j.medntd.2020.100034.

8. Tousoulis, D.; Kampoli, A.-M.; Tentolouris Nikolaos Papageorgiou, C.; Stefanadis, C. The role of nitric oxide on endothelial function. Current vascular pharmacology 2012, 10, 4-18.

9. Vita, J.A. Endothelial function. Circulation 2011, 124, e906-e912.

10. Incalza, M.A.; D'Oria, R.; Natalicchio, A.; Perrini, S.; Laviola, L.; Giorgino, F. Oxidative stress and reactive oxygen species in endothelial dysfunction associated with cardiovascular and metabolic diseases. Vascular pharmacology 2018, 100, 1-19, doi:10.1016/j.vph.2017.05.005. 
11. Ahmad, A.; Dempsey, S.K.; Daneva, Z.; Azam, M.; Li, N.; Li, P.-L.; Ritter, J.K. Role of nitric oxide in the cardiovascular and renal systems. International journal of molecular sciences 2018, 19, 2605.

12. Little, P.J.; Askew, C.D.; Xu, S.; Kamato, D. Endothelial Dysfunction and Cardiovascular Disease: History and Analysis of the Clinical Utility of the Relationship. Biomedicines 2021, 9, 699.

13. Nakagawa, T.; Tanabe, K.; Croker, B.P.; Johnson, R.J.; Grant, M.B.; Kosugi, T.; Li, Q. Endothelial dysfunction as a potential contributor in diabetic nephropathy. Nature Reviews Nephrology 2011, 7, 36-44.

14. Farghadan, A.; Arzani, A. The combined effect of wall shear stress topology and magnitude on cardiovascular mass transport. International Journal of Heat and Mass Transfer 2019, 131, 252-260.

15. Ruggiero, A.D.; Key, C.-C.C.; Kavanagh, K. Adipose tissue macrophage polarization in healthy and unhealthy obesity. Frontiers in Nutrition 2021, 8

16. Xue, Q.; Yan, Y.; Zhang, R.; Xiong, H. Regulation of iNOS on immune cells and its role in diseases. International journal of molecular sciences 2018, 19, 3805.

17. Mittal, M.; Siddiqui, M.R.; Tran, K.; Reddy, S.P.; Malik, A.B. Reactive oxygen species in inflammation and tissue injury. Antioxidants \& redox signaling 2014, 20, 1126-1167.

18. Yang, T.; Zelikin, A.N.; Chandrawati, R. Progress and Promise of Nitric Oxide-Releasing Platforms. Adv Sci (Weinh) 2018, 5, 1701043, doi:10.1002/advs.201701043.

19. Yang, Z.; Yang, Y.; Xiong, K.; Li, X.; Qi, P.; Tu, Q.; Jing, F.; Weng, Y.; Wang, J.; Huang, N. Nitric oxide producing coating mimicking endothelium function for multifunctional vascular stents. Biomaterials 2015, 63, 80-92, doi:10.1016/j.biomaterials.2015.06.016.

20. Zhang, F.; Zhang, Q.; Li, X.; Huang, N.; Zhao, X.; Yang, Z. Mussel-inspired dopamine-Cu(II) coatings for sustained in situ generation of nitric oxide for prevention of stent thrombosis and restenosis. Biomaterials 2019, 194, 117-129, doi:10.1016/j.biomaterials.2018.12.020.

21. Elnaggar, M.A.; Seo, S.H.; Gobaa, S.; Lim, K.S.; Bae, I.H.; Jeong, M.H.; Han, D.K.; Joung, Y.K. Nitric Oxide Releasing Coronary Stent: A New Approach Using Layer-by-Layer Coating and Liposomal Encapsulation. Small 2016, 12, 6012-6023, doi:10.1002/smll.201600337.

22. Naghavi, N.; de Mel, A.; Alavijeh, O.S.; Cousins, B.G.; Seifalian, A.M. Nitric oxide donors for cardiovascular implant applications. Small 2013, 9, 22-35, doi:10.1002/smll.201200458.

23. Maruf, A.; Wang, Y.; Yin, T.; Huang, J.; Wang, N.; Durkan, C.; Tan, Y.; Wu, W.; Wang, G. Atherosclerosis Treatment with Stimuli-Responsive Nanoagents: Recent Advances and Future Perspectives. Adv Healthc Mater 2019, 8, e1900036, doi:10.1002/adhm.201900036.

24. Sreejayan; Rao, M.N. Nitric oxide scavenging by curcuminoids. The Journal of pharmacy and pharmacology 1997, 49, 105-107, doi:10.1111/j.2042-7158.1997.tb06761.x.

25. Gori, T. Exogenous NO Therapy for the Treatment and Prevention of Atherosclerosis. International Journal of Molecular Sciences 2020, 21, 2703, doi:10.3390/ijms21082703.

26. Víteček, J.; Lojek, A.; Valacchi, G.; Kubala, L. Arginine-Based Inhibitors of Nitric Oxide Synthase: Therapeutic Potential and Challenges. Mediators of Inflammation 2012, 2012, 318087.

27. Li, F.; Guo, X.; Chen, S.-Y.J.F.i.c.m. Function and therapeutic potential of mesenchymal stem cells in atherosclerosis. 2017, 4,

32.

28. Midgley, A.C.; Wei, Y.; Li, Z.; Kong, D.; Zhao, Q. Nitric-oxide-releasing biomaterial regulation of the stem cell microenvironment in regenerative medicine. Advanced Materials 2020, 32, 1805818.

29. Thijssen, D.H.; Black, M.A.; Pyke, K.E.; Padilla, J.; Atkinson, G.; Harris, R.A.; Parker, B.; Widlansky, M.E.; Tschakovsky, M.E.; Green, D.J. Assessment of flow-mediated dilation in humans: a methodological and physiological guideline. Am J Physiol Heart Circ Physiol 2011, 300, H2-12.

30. Thijssen, D.H.J.; Bruno, R.M.; van Mil, A.C.C.M.; Holder, S.M.; Faita, F.; Greyling, A.; Zock, P.L.; Taddei, S.; Deanfield, J.E.; Luscher, T.; et al. Expert consensus and evidence-based recommendations for the assessment of flow-mediated dilation in humans. European Heart Journal 2019, 40, 2534-2547, doi:10.1093/eurheartj/ehz350.

31. Qian, S.; Ma, T.; Zhang, N.; Liu, X.; Zhao, P.; Li, X.; Chen, D.; Hu, L.; Chang, L.; Xu, L. Spatiotemporal transfer of nitric oxide in patient-specific atherosclerotic carotid artery bifurcations with MRI and computational fluid dynamics modeling. Computers in Biology and Medicine 2020, 125, 104015.

32. Liu, X.; Wang, Z.; Zhao, P.; Fan, Z.; Sun, A.; Zhan, F.; Fan, Y.; Deng, X. Nitric oxide transport in normal human thoracic aorta: effects of hemodynamics and nitric oxide scavengers. PloS one 2014, 9, e112395.

33. Liu, X.; Fan, Y.; Xu, X.Y.; Deng, X. Nitric oxide transport in an axisymmetric stenosis. Journal of the Royal Society Interface 2012, 9, 2468-2478.

34. Plank, M.J.; Wall, D.J.N.; David, T. The role of endothelial calcium and nitric oxide in the localisation of atherosclerosis. Mathematical Biosciences 2007, 207, 26-39, doi:https://doi.org/10.1016/j.mbs.2006.08.017.

35. Vidanapathirana, A.K.; Psaltis, P.J.; Bursill, C.A.; Abell, A.D.; Nicholls, S.J. Cardiovascular bioimaging of nitric oxide: Achievements, challenges, and the future. Medicinal Research Reviews 2021, 41, 435-463.

36. Yang, N.; Vafai, K. Modeling of low-density lipoprotein (LDL) transport in the artery-effects of hypertension. International Journal of Heat and Mass Transfer 2006, 49, 850-867. 
37. Liu, X.; Pu, F.; Fan, Y.; Deng, X.; Li, D.; Li, S. A numerical study on the flow of blood and the transport of LDL in the human aorta: the physiological significance of the helical flow in the aortic arch. American Journal of Physiology-Heart and Circulatory Physiology 2009, 297, H163-H170.

38. Chen, X.; Zhuang, J.; Huang, H.; Wu, Y. Fluid-structure interactions (FSI) based study of low-density lipoproteins (LDL) uptake in the left coronary artery. Scientific reports 2021, 11, 1-12.

39. Yazdani, A.; Deng, Y.; Li, H.; Javadi, E.; Li, Z.; Jamali, S.; Lin, C.; Humphrey, J.D.; Mantzoros, C.S.; Em Karniadakis, G. Integrating blood cell mechanics, platelet adhesive dynamics and coagulation cascade for modelling thrombus formation in normal and diabetic blood. Journal of the Royal Society Interface 2021, 18, 20200834.

40. Sun, X.; Ma, T.; Liu, Z.; Wu, X.; Zhang, B.; Zhu, S.; Li, F.; Chen, M.; Zheng, Y.; Liu, X. Sequential numerical simulation of vascular remodeling and thrombosis in unconventional hybrid repair of ruptured middle aortic syndrome. Medical Engineering \& Physics 2021, 94, 87-95.

41. Menichini, C.; Cheng, Z.; Gibbs, R.G.; Xu, X.Y. Predicting false lumen thrombosis in patient-specific models of aortic dissection. Journal of The Royal Society Interface 2016, 13, 20160759.

42. Smith, K.M.; Moore, L.C.; Layton, H.E. Advective transport of nitric oxide in a mathematical model of the afferent arteriole. American Journal of Physiology-Renal Physiology 2003, 284, F1080-F1096.

43. Chen, X.; Buerk, D.G.; Barbee, K.A.; Kirby, P.; Jaron, D. 3D network model of NO transport in tissue. Medical \& biological engineering \& computing 2011, 49, 633-647.

44. Sriram, K.; Vázquez, B.Y.S.; Yalcin, O.; Johnson, P.C.; Intaglietta, M.; Tartakovsky, D.M. The effect of small changes in hematocrit on nitric oxide transport in arterioles. Antioxidants \& redox signaling 2011, 14, 175-185.

45. Fadel, A.; Barbee, K.; Jaron, D. A computational model of nitric oxide production and transport in a parallel plate flow chamber. Annals of biomedical engineering 2009, 37, 943-954.

46. Plata, A.; Sherwin, S.; Krams, R. Endothelial nitric oxide production and transport in flow chambers: the importance of convection. Annals of biomedical engineering 2010, 38, 2805-2816.

47. Qiao, H.; Liu, C.; Zhao, H.; Feng, D.D. Model and verification of the NO distribution in curved blood vessel. IFACPapersOnLine 2018, 51, 237-240, doi:https://doi.org/10.1016/j.ifacol.2018.11.636.

48. Wei, Y.-j.; He, Y.; Tang, Y.-1.; Mu, L.-z. Finite element analysis of nitric oxide (NO) transport in system of permeable capillary and tissue. Journal of Hydrodynamics 2018, 30, 722-737, doi:10.1007/s42241-018-0076-8.

49. Wei, Y.; Mu, L.; Tang, Y.; Shen, Z.; He, Y. Computational analysis of nitric oxide biotransport in a microvessel influenced by red blood cells. Microvascular research 2019, 125, 103878.

50. Guglielmo, M.; Lin, A.; Dey, D.; Baggiano, A.; Fusini, L.; Muscogiuri, G.; Pontone, G. Epicardial fat and coronary artery disease: Role of cardiac imaging. Atherosclerosis 2021.

51. Queiroz, M.; Sena, C.M. Perivascular adipose tissue in age-related vascular disease. Ageing research reviews 2020, 59, 101040.

52. Barp, C.G.; Bonaventura, D.; Assreuy, J. NO, ROS, RAS, and PVAT: more than a soup of letters. Frontiers in Physiology 2021, $12,108$.

53. Celermajer D S , S.K.E., Gooch V M. . Non-invasive detection of endothelial dysfunction in children and adults at risk of atherosclerosis. Lancet (North American Edition) 1992, 340, 1111-1115.

54. Cox, D.A.; Vita, J.A.; Treasure, C.B. Atherosclerosis impairs flow-mediated dilation of coronary arteries in humans. Circulation $1989,80,458-465$.

55. Vita, J.A.; Treasure, C.B.; Nabel, E.G.; McLenachan, J.M.; Fish, R.D.; Yeung, A.C.; Vekshtein, V.I.; Selwyn, A.P.; Ganz, P. Coronary vasomotor response to acetylcholine relates to risk factors for coronary artery disease. Circulation 1990, 81, 491-497.

56. Pyke, K.E.; Tschakovsky, M.E. Peak vs. total reactive hyperemia: which determines the magnitude of flow-mediated dilation? Journal of Applied Physiology 2007, 102, 1510-1519.

57. Padilla, J.; Johnson, B.D.; Newcomer, S.C.; Wilhite, D.P.; Wallace, J.P. Normalization of flow-mediated dilation to shear stress area under the curve eliminates the impact of variable hyperemic stimulus. Cardiovascular Ultrasound 2008, 6, 44-44.

58. Atkinson, G.; Batterham, A.M.; Black, M.A.; Cable, N.T.; Hopkins, N.D.; Dawson, E.A.; Thijssen, D.H.J.; Jones, H.; Tinken, T.M.; Green, D.J. Is the ratio of flow-mediated dilation and shear rate a statistically sound approach to normalization in cross-sectional studies on endothelial function? Journal of Applied Physiology 2009, 107, 1893-1899.

59. Harris, R.A.; Padilla, J. Proper "normalization" of flow-mediated dilation for shear. Journal of Applied Physiology 2007, 103, 1108-1108.

60. Atkinson, G.; Batterham, A.M.; Thijssen, D.H.J.; Green, D.J. A new approach to improve the specificity of flow-mediated dilation for indicating endothelial function in cardiovascular research. J Hypertens 2013, 31, 287-291, doi:10.1097/hjh.0b013e32835b8164.

61. Atkinson, G.; Batterham, A.M. Allometric scaling of diameter change in the original flow-mediated dilation protocol. Atherosclerosis 2013, 226, 425-427.

62. Yamazaki, Y.; Kondo, Y.; Kamiyama, Y. Estimation of shear-stress-induced endothelial nitric oxide production from flowmediated dilation. In Proceedings of the 2013 35th Annual International Conference of the IEEE Engineering in Medicine and Biology Society (EMBC), 2013; pp. 4521-4524.

63. Yamazaki, Y.; Kamiyama, Y. Mathematical model of wall shear stress-dependent vasomotor response based on physiological mechanisms. Computers in biology and medicine 2014, 45, 126-135.

64. Van Brackle, C.H.; Harris, R.A.; Hallow, K.M. Exposure-response modeling of flow-mediated dilation provides an unbiased and informative measure of endothelial function. Journal of Applied Physiology 2017, 122, 1292-1303. 
65. Jin, W.; Chowienczyk, P.; Alastruey, J. An in silico simulation of flow-mediated dilation reveals that blood pressure and other factors may influence the response independent of endothelial function. American Journal of Physiology-Heart and Circulatory Physiology 2020, 318, H1337-H1345.

66. Jin, W. Cardiovascular Function Assessment using Computational Blood Flow Modelling and Machine Learning. King's College London, 2021.

67. Sidnawi, B.; Chen, Z.; Sehgal, C.; Wu, Q. Characterization of arterial flow mediated dilation via a physics-based model. Journal of the mechanical behavior of biomedical materials 2020, 107, 103756.

68. Sidnawi, B.; Chen, Z.; Sehgal, C.; Santhanam, S.; Wu, Q. On the modeling of mechanotransduction in flow-mediated dilation. Journal of the Mechanical Behavior of Biomedical Materials 2021, 120, 104606.

69. Ma, T.; Liu, X.; Ren, Q.; Zhang, Z.; Sun, X.; Zheng, Y.; Deng, X.; Yu, X.; Fan, Y. Flow-mediated dilation analysis coupled with nitric oxide transport to enhance the assessment of endothelial function. Journal of Applied Physiology 2021, 131, 1-14.

70. Cui, J.; Hu, K.; Sun, J.-J.; Qu, L.-L.; Li, D.-W. SERS nanoprobes for the monitoring of endogenous nitric oxide in living cells. Biosensors and Bioelectronics 2016, 85, 324-330.

71. Xu, Q.; Liu, W.; Li, L.; Zhou, F.; Zhou, J.; Tian, Y. Ratiometric SERS imaging and selective biosensing of nitric oxide in live cells based on trisoctahedral gold nanostructures. Chemical Communications 2017, 53, 1880-1883.

72. Chen, H.-Y.; Kouadio Fodjo, E.; Jiang, L.; Chang, S.; Li, J.-B.; Zhan, D.-S.; Gu, H.-X.; Li, D.-W. Simultaneous Detection of Intracellular Nitric Oxide and Peroxynitrite by a Surface-Enhanced Raman Scattering Nanosensor with Dual Reactivity. ACS sensors 2019, 4, 3234-3239.

73. Majka, Z.; Czamara, K.; Wegrzyn, P.; Litwinowicz, R.; Janus, J.; Chlopicki, S.; Kaczor, A. A new approach to study human perivascular adipose tissue of the internal mammary artery by fiber-optic Raman spectroscopy supported by spectral modelling. Analyst 2021, 146, 270-276.

74. Czamara, K.; Majka, Z.; Sternak, M.; Koziol, M.; Kostogrys, R.B.; Chlopicki, S.; Kaczor, A. Distinct chemical changes in abdominal but not in thoracic aorta upon atherosclerosis studied using fiber optic raman spectroscopy. International journal of molecular sciences 2020, 21, 4838 .

75. Goshi, E.; Zhou, G.; He, Q. Nitric oxide detection methods in vitro and in vivo. Medical gas research 2019, 9, 192.

76. Fujita, S.; Roerig, D.L.; Chung, W.W.; Bosnjak, Z.J.; Stowe, D.F. Volatile anesthetics do not alter bradykinin-induced release of nitric oxide or L-citrulline in crystalloid perfused guinea pig hearts. The Journal of the American Society of Anesthesiologists 1998, $89,421-433$.

77. Takarada, S.; Imanishi, T.; Goto, M.; Mochizuki, S.; Ikejima, H.; Tsujioka, H.; Kuroi, A.; Takeshita, T.; Akasaka, T. First evaluation of real-time nitric oxide changes in the coronary circulation in patients with non-ischaemic dilated cardiomyopathy using a catheter-type sensor. European heart journal 2010, 31, 2862-2870.

78. Tang, L.; Li, Y.; Xie, H.; Shu, Q.; Yang, F.; Liu, Y.-1.; Liang, F.; Wang, H.; Huang, W.; Zhang, G.-J. A sensitive acupuncture needle microsensor for real-time monitoring of nitric oxide in acupoints of rats. Scientific reports 2017, 7, 1-10.

79. Li, R.; Qi, H.; Ma, Y.; Deng, Y.; Liu, S.; Jie, Y.; Jing, J.; He, J.; Zhang, X.; Wheatley, L. A flexible and physically transient electrochemical sensor for real-time wireless nitric oxide monitoring. Nature communications 2020, 11, 1-11.

80. Li, R.; Qi, H.; Ma, Y.; Deng, Y.; Liu, S.; Jie, Y.; Jing, J.; He, J.; Zhang, X.; Wheatley, L.; et al. A flexible and physically transient electrochemical sensor for real-time wireless nitric oxide monitoring. Nature Communications 2020, 11, 3207, doi:10.1038/s41467-02017008-8.

81. Hedenstierna, G.; Chen, L.; Hedenstierna, M.; Scaramuzzo, G. Treatment of COVID-19 by inhaled NO to reduce shunt? American Journal of Respiratory and Critical Care Medicine 2020, 202, 618-618.

82. Roberts Jr, J.; Polaner, D.M.; Zapol, W.; Lang, P. Inhaled nitric oxide in persistent pulmonary hypertension of the newborn. The Lancet 1992, 340, 818-819.

83. Germann, P.; Braschi, A.; Della Rocca, G.; Dinh-Xuan, A.T.; Falke, K.; Frostell, C.; Gustafsson, L.E.; Hervé, P.; Jolliet, P.; Kaisers, U. Inhaled nitric oxide therapy in adults: European expert recommendations. Intensive care medicine 2005, 31, 1029-1041.

84. Lai, M.-Y.; Chu, S.-M.; Lakshminrusimha, S.; Lin, H.-C. Beyond the inhaled nitric oxide in persistent pulmonary hypertension of the newborn. Pediatrics \& Neonatology 2018, 59, 15-23.

85. Carter, B.G.; Swain, R.; Hislop, J.; Escudie, M.; H Williams, R. Delivery of Inhaled Nitric Oxide During MRI to Ventilated Neonates and Infants. Respiratory Care 2021, respcare.08408, doi:10.4187/respcare.08408.

86. Schäfer, M.; Frank, B.S.; Ivy, D.D.; Abman, S.H.; Stenmark, K.R.; Mitchell, M.B.; Browne, L.P.; Barker, A.J.; Hunter, K.S.; Kheyfets, V.; et al. Short-Term Effects of Inhaled Nitric Oxide on Right Ventricular Flow Hemodynamics by 4-Dimensional-Flow Magnetic Resonance Imaging in Children With Pulmonary Arterial Hypertension. Journal of the American Heart Association 2021, 10, e020548, doi:10.1161/jaha.120.020548.

87. Buess, A.; Van Muylem, A.; Nonclercq, A.; Haut, B. Modeling of the transport and exchange of a gas species in lungs with an asymmetric branching pattern. application to nitric oxide. Frontiers in physiology 2020, 11.

88. Lei, C.; Su, B.; Dong, H.; Fakhr, B.S.; Grassi, L.G.; Di Fenza, R.; Gianni, S.; Pinciroli, R.; Vassena, E.; Morais, C.C.A.; et al. Protocol for a randomized controlled trial testing inhaled nitric oxide therapy in spontaneously breathing patients with COVID-19. medRxiv 2020, 2020.2003.2010.20033522, doi:10.1101/2020.03.10.20033522.

89. Parikh, R.; Wilson, C.; Weinberg, J.; Gavin, D.; Murphy, J.; Reardon, C.C. Inhaled nitric oxide treatment in spontaneously breathing COVID-19 patients. Therapeutic Advances in Respiratory Disease 2020, 14, 1753466620933510. 
90. Bagate, F.; Tuffet, S.; Masi, P.; Perier, F.; Razazi, K.; de Prost, N.; Carteaux, G.; Payen, D.; Mekontso Dessap, A. Rescue therapy with inhaled nitric oxide and almitrine in COVID-19 patients with severe acute respiratory distress syndrome. Annals of Intensive Care 2020, 10, 151, doi:10.1186/s13613-020-00769-2.

91. Hedenstierna, G.; Chen, L.; Hedenstierna, M.; Lieberman, R.; Fine, D.H. Nitric oxide dosed in short bursts at high concentrations may protect against Covid 19. Nitric Oxide 2020, 103, 1-3, doi:https://doi.org/10.1016/j.niox.2020.06.005.

92. Mahla, R.S.J.I.j.o.c.b. Stem cells applications in regenerative medicine and disease therapeutics. 2016, 2016.

93. Samsonraj, R.M.; Raghunath, M.; Nurcombe, V.; Hui, J.H.; van Wijnen, A.J.; Cool, S.M.J.S.c.t.m. Concise review: multifaceted characterization of human mesenchymal stem cells for use in regenerative medicine. 2017, 6, 2173-2185.

94. Lin, Y.; Zhu, W.; Chen, X.J.S.c.r.; therapy. The involving progress of MSCs based therapy in atherosclerosis. 2020, 11, 1-13.

95. Salvolini, E.; Orciani, M.; Vignini, A.; Mattioli-Belmonte, M.; Mazzanti, L.; Di Primio, R.J.E.d. Skin-derived mesenchymal stem cells (S-MSCs) induce endothelial cell activation by paracrine mechanisms. 2010, 19, 848-850.

96. Kirwin, T.; Gomes, A.; Amin, R.; Sufi, A.; Goswami, S.; Wang, B.J.R.M. Mechanisms underlying the therapeutic potential of mesenchymal stem cells in atherosclerosis. 2021, 16, 669-682.

97. Lin, Y.-L.; Yet, S.-F.; Hsu, Y.-T.; Wang, G.-J.; Hung, S.-C.J.S.c.t.m. Mesenchymal stem cells ameliorate atherosclerotic lesions via restoring endothelial function. 2015, 4, 44-55.

98. Abdel-Kawi, S.H.; Hashem, K.S.J.I.j.o.s.c. Possible therapeutic effect of stem cell in atherosclerosis in albino rats. A histological and immunohistochemical study. 2015, 8, 200.

99. Huang, Q.; Cheng, X.; Luo, C.; Yang, S.; Li, S.; Wang, B.; Yuan, X.; Yang, Y.; Wen, Y.; Liu, R.J.S.c.r.; et al. Placental chorionic plate-derived mesenchymal stem cells ameliorate severe acute pancreatitis by regulating macrophage polarization via secreting TSG6. 2021, 12, 1-17.

100. Ma, J.; Chen, L.; Zhu, X.; Li, Q.; Hu, L.; Li, H.J.A.B.e.B.S. Mesenchymal stem cell-derived exosomal miR-21a-5p promotes M2 macrophage polarization and reduces macrophage infiltration to attenuate atherosclerosis. 2021, 53, 1227-1236.

101. Yun, C.W.; Lee, S.H. Enhancement of Functionality and Therapeutic Efficacy of Cell-Based Therapy Using Mesenchymal Stem Cells for Cardiovascular Disease. Int J Mol Sci 2019, 20, doi:10.3390/ijms20040982.

102. Jang, S.; de l'Hortet, A.C.; Soto-Gutierrez, A. Induced Pluripotent Stem Cell-Derived Endothelial Cells Overview, Current Advances, Applications, and Future Directions. American Journal of Pathology 2019, 189, 502-512, doi:10.1016/j.ajpath.2018.12.004.

103. Zakrzewski, W.; Dobrzyński, M.; Szymonowicz, M.; Rybak, Z.J.S.c.r.; therapy. Stem cells: past, present, and future. 2019, 10, 122.

104. Psaltis, P.J.; Simari, R.D.J.C.r. Vascular wall progenitor cells in health and disease. 2015, 116, $1392-1412$.

105. Xing, X.; Li, Z.; Yang, X.; Li, M.; Liu, C.; Pang, Y.; Zhang, L.; Li, X.; Liu, G.; Xiao, Y.J.A. Adipose-derived mesenchymal stem cells-derived exosome-mediated microRNA-342-5p protects endothelial cells against atherosclerosis. 2020, $12,3880$.

106. Yang, W.Z.; Yin, R.H.; Zhu, X.Y.; Yang, S.N.; Wang, J.; Zhou, Z.F.; Pan, X.D.; Ma, A.J. Mesenchymal stem-cell-derived exosomal miR-145 inhibits atherosclerosis by targeting JAM-A. Molecular Therapy-Nucleic Acids 2021, 23, 119-131, doi:10.1016/j.omtn.2020.10.037.

107. Moghaddam, A.S.; Afshari, J.T.; Esmaeili, S.A.; Saburi, E.; Joneidi, Z.; Momtazi-Borojeni, A.A. Cardioprotective microRNAs: Lessons from stem cell-derived exosomal microRNAs to treat cardiovascular disease. Atherosclerosis 2019, 285, 1-9, doi:10.1016/j.atherosclerosis.2019.03.016.

108. Baglio, S.R.; Pegtel, D.M.; Baldini, N.J.F.i.p. Mesenchymal stem cell secreted vesicles provide novel opportunities in (stem) cellfree therapy. 2012, 3, 359.

109. Ling, H.; Guo, Z.Y.; Tan, L.L.; Cao, Q.D.; Song, C.L. Stem cell-derived exosomes: Role in the pathogenesis and treatment of atherosclerosis. International Journal of Biochemistry \& Cell Biology 2021, 130, doi:10.1016/j.biocel.2020.105884.

110. Lu, X.J. The Role of Exosomes and Exosome-derived microRNAs in Atherosclerosis. Current Pharmaceutical Design 2017, 23, 6182-6193, doi:10.2174/1381612823666170413125507.

111. Phinney, D.G.; Pittenger, M.F. Concise Review: MSC-Derived Exosomes for Cell-Free Therapy. Stem Cells 2017, 35, 851-858, doi:10.1002/stem.2575.

112. Regmi, S.; Pathak, S.; Kim, J.O.; Yong, C.S.; Jeong, J.H. Mesenchymal stem cell therapy for the treatment of inflammatory diseases: Challenges, opportunities, and future perspectives. European journal of cell biology 2019, 98, 151041, doi:10.1016/j.ejcb.2019.04.002.

113. Caplan, H.; Olson, S.D.; Kumar, A.; George, M.; Prabhakara, K.S.; Wenzel, P.; Bedi, S.; Toledano-Furman, N.E.; Triolo, F.; Kamhieh-Milz, J.; et al. Mesenchymal Stromal Cell Therapeutic Delivery: Translational Challenges to Clinical Application. Front Immunol 2019, 10, 1645-1645, doi:10.3389/fimmu.2019.01645.

114. Regmi, S.; Cao, J.; Pathak, S.; Gupta, B.; Kumar Poudel, B.; Tung, P.T.; Yook, S.; Park, J.-B.; Yong, C.S.; Kim, J.O.; et al. A threedimensional assemblage of gingiva-derived mesenchymal stem cells and NO-releasing microspheres for improved differentiation. International journal of pharmaceutics 2017, 520, 163-172, doi:10.1016/j.ijpharm.2017.02.014.

115. Sato, K.; Maeda, M.; Kamata, E.; Ishii, S.; Yanagisawa, K.; Kitajima, K.; Hara, T. Nitric Oxide and a Conditioned Medium Affect the Hematopoietic Development in a Microfluidic Mouse Embryonic Stem Cell/OP9 Co-Cultivation System. Micromachines 2020, 11, doi:10.3390/mi11030305.

116. Zhang, K.; Chen, X.; Li, H.; Feng, G.; Nie, Y.; Wei, Y.; Li, N.; Han, Z.; Han, Z.-c.; Kong, D.; et al. A nitric oxide-releasing hydrogel for enhancing the therapeutic effects of mesenchymal stem cell therapy for hindlimb ischemia. Acta biomaterialia 2020, 113, 289-304, doi:https://doi.org/10.1016/j.actbio.2020.07.011. 
117. Gori, T. Exogenous NO Therapy for the Treatment and Prevention of Atherosclerosis. International Journal of Molecular Sciences 2020, 21, doi:10.3390/ijms21082703.

118. Knorr, M.; Hausding, M.; Kröller-Schuhmacher, S.; Steven, S.; Oelze, M.; Heeren, T.; Scholz, A.; Gori, T.; Wenzel, P.; Schulz, E.; et al. Nitroglycerin-induced endothelial dysfunction and tolerance involve adverse phosphorylation and S-Glutathionylation of endothelial nitric oxide synthase: beneficial effects of therapy with the AT1 receptor blocker telmisartan. Arteriosclerosis, thrombosis, and vascular biology 2011, 31, 2223-2231, doi:10.1161/atvbaha.111.232058.

119. Gori, T.; Daiber, A.; Di Stolfo, G.; Sicuro, S.; Dragoni, S.; Lisi, M.; Münzel, T.; Forconi, S.; Parker, J.D. Nitroglycerine causes mitochondrial reactive oxygen species production: in vitro mechanistic insights. The Canadian journal of cardiology 2007, 23, 990992, doi:10.1016/s0828-282x(07)70862-0.

120. Lundberg, J.O.; Gladwin, M.T.; Weitzberg, E. Strategies to increase nitric oxide signalling in cardiovascular disease. Nature Reviews Drug Discovery 2015, 14, 623-641, doi:10.1038/nrd4623.

121. Ramms, B.; Gordts, P.L. Dietary nitrate struggles in atherosclerosis. Atherosclerosis 2016, 245, 71-73, doi:10.1016/j.atherosclerosis.2015.12.007.

122. Liu, Y.; Croft, K.D.; Hodgson, J.M.; Mori, T.; Ward, N.C. Mechanisms of the protective effects of nitrate and nitrite in cardiovascular and metabolic diseases. Nitric oxide : biology and chemistry 2020, 96, 35-43, doi:10.1016/j.niox.2020.01.006.

123. Lenz, M.; Kaun, C.; Krychtiuk, K.A.; Haider, P.; Brekalo, M.; Maier, N.; Goederle, L.; Binder, C.J.; Huber, K.; Hengstenberg, C.J.B. Effects of nicorandil on inflammation, apoptosis and atherosclerotic plaque progression. 2021, 9, 120.

124. Sekiya, M.; Sato, M.; Funada, J.; Ohtani, T.; Akutsu, H.; Watanabe, K.J.J.o.c.p. Effects of the long-term administration of nicorandil on vascular endothelial function and the progression of arteriosclerosis. 2005, 46, 63-67.

125. Roth, L.; Van der Donckt, C.; Emini Veseli, B.; Van Dam, D.; De Deyn, P.P.; Martinet, W.; Herman, A.G.; De Meyer, G.R.Y. Nitric oxide donor molsidomine favors features of atherosclerotic plaque stability and reduces myocardial infarction in mice. Vascular pharmacology 2019, 118-119, 106561, doi:10.1016/j.vph.2019.05.001.

126. Fitzhugh, A.L.; Keefer, L.K. Diazeniumdiolates: pro- and antioxidant applications of the "NONOates". Free radical biology \& medicine 2000, 28, 1463-1469, doi:10.1016/s0891-5849(00)00251-3.

127. Yang, T.; Zelikin, A.N.; Chandrawati, R. Progress and Promise of Nitric Oxide-Releasing Platforms. Advanced Science 2018, 5, doi:10.1002/advs.201701043.

128. Yang, C.; Jeong, S.; Ku, S.; Lee, K.; Park, M.H. Use of gasotransmitters for the controlled release of polymer-based nitric oxide carriers in medical applications. Journal of controlled release : official journal of the Controlled Release Society 2018, 279, 157-170, doi:10.1016/j.jconrel.2018.04.025.

129. Ding, Z.; He, K.; Duan, Y.; Shen, Z.; Cheng, J.; Zhang, G.; Hu, J. Photo-degradable micelles for co-delivery of nitric oxide and doxorubicin. Journal of materials chemistry. B 2020, 8, 7009-7017, doi:10.1039/d0tb00817f.

130. Chen, Y.; Fang, L.; Zhou, W.; Chang, J.; Zhang, X.; He, C.; Chen, C.; Yan, R.; Yan, Y.; Lu, Y.; et al. Nitric oxide-releasing micelles with intelligent targeting for enhanced anti-tumor effect of cisplatin in hypoxia. Journal of nanobiotechnology 2021, 19, 246, doi:10.1186/s12951-021-00989-z.

131. Gao, M.; Liu, S.; Fan, A.; Wang, Z.; Zhao, Y. Nitric oxide-releasing graft polymer micelles with distinct pendant amphiphiles. RSC Advances 2015, 5, 67041-67048, doi:10.1039/C5RA13341F.

132. Kesharwani, P.; Jain, K.; Jain, N.K.J.P.i.P.S. Dendrimer as nanocarrier for drug delivery. 2014, 39, $268-307$.

133. Katsumi, H.; Takashima, R.; Suzuki, H.; Hirai, N.; Matsuura, S.; Kimura, H.; Morishita, M.; Yamamoto, A. S-nitrosylated 1serine-modified dendrimer as a kidney-targeting nitric oxide donor for prevention of renal ischaemia/reperfusion injury. Free radical research 2020, 54, 841-847, doi:10.1080/10715762.2019.1697437.

134. Worley, B.V.; Soto, R.J.; Kinsley, P.C.; Schoenfisch, M.H. Active Release of Nitric Oxide-Releasing Dendrimers from Electrospun Polyurethane Fibers. ACS biomaterials science \& engineering 2016, 2, 426-437, doi:10.1021/acsbiomaterials.6b00032.

135. Duan, S.; Cai, S.; Xie, Y.; Bagby, T.; Ren, S.; Forrest, M.L. Synthesis and characterization of a multi-arm poly(acrylic acid) star polymer for application in sustained delivery of cisplatin and a nitric oxide prodrug. Journal of polymer science. Part A, Polymer chemistry 2012, 50, 2715-2724, doi:10.1002/pola.26059.

136. Nguyen, T.K.; Selvanayagam, R.; Ho, K.K.K.; Chen, R.; Kutty, S.K.; Rice, S.A.; Kumar, N.; Barraud, N.; Duong, H.T.T.; Boyer, C. Co-delivery of nitric oxide and antibiotic using polymeric nanoparticles. Chemical science 2016, 7, 1016-1027, doi:10.1039/c5sc02769a.

137. Oliver, S.; Pham, T.T.P.; Li, Y.; Xu, F.J.; Boyer, C. More than skin deep: using polymers to facilitate topical delivery of nitric oxide. Biomaterials science 2021, 9, 391-405, doi:10.1039/d0bm01197e.

138. Lautner, G.; Meyerhoff, M.E.; Schwendeman, S.P. Biodegradable poly(lactic-co-glycolic acid) microspheres loaded with Snitroso-N-acetyl-D-penicillamine for controlled nitric oxide delivery. Journal of controlled release : official journal of the Controlled Release Society 2016, 225, 133-139, doi:10.1016/j.jconrel.2015.12.056.

139. Š́rová, M.; Horková, V.; Etrych, T.; Chytil, P.; Ř́hová, B.; Studenovský, M. Polymer donors of nitric oxide improve the treatment of experimental solid tumours with nanosized polymer therapeutics. Journal of drug targeting 2017, 25, 796-808, doi:10.1080/1061186x.2017.1358724.

140. Neha, D.; Momin, M.; Khan, T.; Gharat, S.; Ningthoujam, R.S.; Omri, A. Metallic nanoparticles as drug delivery system for the treatment of cancer. Expert opinion on drug delivery 2021, 18, 1261-1290, doi:10.1080/17425247.2021.1912008.

141. Anderson, S.D.; Gwenin, V.V.; Gwenin, C.D. Magnetic Functionalized Nanoparticles for Biomedical, Drug Delivery and Imaging Applications. Nanoscale research letters 2019, 14, 188, doi:10.1186/s11671-019-3019-6.

142. Khan, I.; Saeed, K.; Khan, I.J.A.j.o.c. Nanoparticles: Properties, applications and toxicities. 2019, 12, 908-931. 
143. Soto, R.J.; Yang, L.; Schoenfisch, M.H. Functionalized Mesoporous Silica via an Aminosilane Surfactant Ion Exchange Reaction: Controlled Scaffold Design and Nitric Oxide Release. ACS applied materials \& interfaces 2016, 8, 2220-2231, doi:10.1021/acsami.5b10942.

144. Midgley, A.C.; Wei, Y.; Li, Z.; Kong, D.; Zhao, Q. Nitric-Oxide-Releasing Biomaterial Regulation of the Stem Cell Microenvironment in Regenerative Medicine. Advanced materials (Deerfield Beach, Fla.) 2020, 32, e1805818, doi:10.1002/adma.201805818.

145. Nichols, S.P.; Storm, W.L.; Koh, A.; Schoenfisch, M.H. Local delivery of nitric oxide: targeted delivery of therapeutics to bone and connective tissues. Advanced drug delivery reviews 2012, 64, 1177-1188, doi:10.1016/j.addr.2012.03.002.

146. Qu, G.; Wu, Q.; Zhao, B.; Miao, J.; Su, L. The promotion effect of novel magnetic nanoparticles on atherosclerotic plaque vulnerability in apolipoprotein E(-/-) mice. Toxicology 2019, 419, 24-31, doi:10.1016/j.tox.2019.03.002.

147. Oh, Y.; Jeong, H.; Lim, S.; Hong, J. Controlled nitric oxide release using poly (lactic-co-glycolic acid) nanoparticles for antiinflammatory effects. Biomacromolecules 2020, 21, 4972-4979.

148. Pant, J.; Goudie, M.J.; Hopkins, S.P.; Brisbois, E.J.; Handa, H. Tunable nitric oxide release from S-nitroso-N-acetylpenicillamine via catalytic copper nanoparticles for biomedical applications. ACS applied materials \& interfaces 2017, 9, 15254-15264.

149. Zhu, T.; Zhou, M.; Gao, W.; Fang, D.; Liu, Z.; Wu, G.; Wan, M.; Mao, C.; Shen, J.J.L. Coronary stents decorated by heparin/NONOate nanoparticles for anticoagulant and endothelialized effects. 2020, 36, 2901-2910.

150. Choi, H.W.; Kim, J.; Kim, J.; Kim, Y.; Song, H.B.; Kim, J.H.; Kim, K.; Kim, W.J. Light-Induced Acid Generation on a Gatekeeper for Smart Nitric Oxide Delivery. ACS Nano 2016, 10, 4199-4208, doi:10.1021/acsnano.5b07483.

151. Qian, M.; Liu, Q.; Wei, Y.; Guo, Z.; Zhao, Q. In-situ biotransformation of nitric oxide by functionalized surfaces of cardiovascular stents. Bioactive materials 2021, 6, 1464-1467, doi:10.1016/j.bioactmat.2020.10.030.

152. Yang, Y.; Gao, P.; Wang, J.; Tu, Q.; Bai, L.; Xiong, K.; Qiu, H.; Zhao, X.; Maitz, M.F.; Wang, H.; et al. Endothelium-Mimicking Multifunctional Coating Modified Cardiovascular Stents via a Stepwise Metal-Catechol-(Amine) Surface Engineering Strategy. Research (Washington, D.C.) 2020, 2020, 9203906, doi:10.34133/2020/9203906.

153. Zhou, Y.; Yang, T.; Liang, K.; Chandrawati, R. Metal-organic frameworks for therapeutic gas delivery. Advanced drug delivery reviews 2021, 171, 199-214, doi:10.1016/j.addr.2021.02.005.

154. Pinto, R.V.; Antunes, F.; Pires, J.; Graça, V.; Brandão, P.; Pinto, M.L. Vitamin B(3) metal-organic frameworks as potential delivery vehicles for therapeutic nitric oxide. Acta biomaterialia 2017, 51, 66-74, doi:10.1016/j.actbio.2017.01.039.

155. Mura, S.; Nicolas, J.; Couvreur, P. Stimuli-responsive nanocarriers for drug delivery. Nature Materials 2013, 12, 991-1003, doi:10.1038/nmat3776.

156. Ji, X.; Zhou, C.; Ji, K.; Aghoghovbia, R.E.; Pan, Z.; Chittavong, V.; Ke, B.; Wang, B. Click and Release: A Chemical Strategy toward Developing Gasotransmitter Prodrugs by Using an Intramolecular Diels-Alder Reaction. Angewandte Chemie (International ed. in English) 2016, 55, 15846-15851, doi:10.1002/anie.201608732.

157. Chandrawati, R.; Chang, J.Y.H.; Reina-Torres, E.; Jumeaux, C.; Sherwood, J.M.; Stamer, W.D.; Zelikin, A.N.; Overby, D.R.; Stevens, M.M. Localized and Controlled Delivery of Nitric Oxide to the Conventional Outflow Pathway via Enzyme Biocatalysis: Toward Therapy for Glaucoma. Advanced materials (Deerfield Beach, Fla.) 2017, 29, doi:10.1002/adma.201604932.

158. Hou, J.; Pan, Y.; Zhu, D.; Fan, Y.; Feng, G.; Wei, Y.; Wang, H.; Qin, K.; Zhao, T.; Yang, Q.J.N.c.b. Targeted delivery of nitric oxide via a 'bump-and-hole'-based enzyme-prodrug pair. 2019, 15, 151-160.

159. Wang, Z.; Lu, Y.; Qin, K.; Wu, Y.; Tian, Y.; Wang, J.; Zhang, J.; Hou, J.; Cui, Y.; Wang, K.; et al. Enzyme-functionalized vascular grafts catalyze in-situ release of nitric oxide from exogenous NO prodrug. Journal of controlled release : official journal of the Controlled Release Society 2015, 210, 179-188, doi:10.1016/j.jconrel.2015.05.283.

160. Dai, Y.; Zhu, Y.; Cheng, J.; Shen, J.; Huang, H.; Liu, M.; Chen, Z.; Liu, Y. Nitric oxide-releasing platinum(IV) prodrug efficiently inhibits proliferation and metastasis of cancer cells. Chemical communications (Cambridge, England) 2020, 56, 14051-14054, doi:10.1039/d0cc05422d.

161. Dang, Y.; Ruan, L.; Tian, Y.; Xu, Z.; Zhang, W. Nitric Oxide Prodrug Delivery and Release Monitoring Based on a GalactoseModified Multifunctional Nanoprobe. Analytical chemistry 2021, 93, 7625-7634, doi:10.1021/acs.analchem.1c00287.

162. Hewlin, R.L.; Ciero, A.; Kizito, J.P. Development of a Two-Way Coupled Eulerian-Lagrangian Computational Magnetic Nanoparticle Targeting Model for Pulsatile Flow in a Patient-Specific Diseased Left Carotid Bifurcation Artery. Cardiovascular Engineering and Technology 2019, 10, 299-313, doi:10.1007/s13239-019-00411-8.

163. Shamloo, A.; Forouzandehmehr, M. Personalised deposition maps for micro- and nanoparticles targeting an atherosclerotic plaque: attributions to the receptor-mediated adsorption on the inflamed endothelial cells. Biomechanics and Modeling in Mechanobiology 2019, 18, 813-828, doi:10.1007/s10237-018-01116-y.

164. Meschi, S.S.; Farghadan, A.; Arzani, A. Flow topology and targeted drug delivery in cardiovascular disease. Journal of Biomechanics 2021, 119, 110307, doi:https://doi.org/10.1016/j.jbiomech.2021.110307. 